\title{
MUJERES: VIOLENCIA DE LA IDENTIFICACIÓN A UN SILENCIO QUE SE HACE CREACIÓN
}

\author{
Lydia Gómez Valverde \\ Miembro del consejo de dirección de CEPYP-UNO \\ (Centro de Trabajo Psicoanalítico)
}

\section{Escuchar}

Mi experiencia como psicoanalista mujer, conjugada con un largo compromiso de trabajo en materia de malos tratos a mujeres, me ha conducido a abordar la problemática de género extrayendo de mi bagaje teórico, clínico y de trabajo en equipo el material con que conceptualizar y proponer modelos de intervención ante tal manifestación que va contra la condición humana: la violencia ejercida contra las mujeres.

Hoy no voy a hablar de los parámetros concretos para la intervención aunque sí me gustaría dejar reseñado que es esencialmente desde una posición de escucha verdadera, escucha de una otredad radical, que resulta posible acceder al milagro de que lo conocido o evidente se torne enigmático y requiera esclarecimiento, y que, sólo desde ahí, desde la extrañeza y la pregunta, pueden las mujeres, una por una, historizar sus acontecimientos singulares y situarlos en un contexto social y político, otorgarles un sentido particular e hilvanarlos con un contexto. Rehacer su historia, investigando a partir de la ocasión e incitaciones de su momento actual, supone extrañarse de lo que había sido aceptado como natural, aunque fuera vivido como condena, y asir las riendas de su subjetividad.

Deconstruir una identidad requiere de respeto y compañía (y por supuesto del acercamiento de recursos), y el primero de los respetos se materializa en la no imposición de nuevas formas de conducta o pensamiento que 
siempre serán las adecuadas, en principio, desde la perspectiva de los/as profesionales, pero que no han podido encarnarse en las sujetos. La intervención prematura de signo educativo y de supresión de carencias tiende por lo general a reforzar la estructura vincular que, si bien no dio lugar al nacimiento de la violencia, sí fundamentó su padecimiento: la estructura de la dependencia.

El trabajo tanto con los equipos que atienden a mujeres maltratadas como con ellas mismas pasa pues por privilegiar las palabras, entrecortadas o balbuceantes al principio, abrumadas por el miedo o la ira, o cargadas de ese saber tan común y dañino que llamamos resignación y, a veces, estadística, pero todas ellas promesa, sin duda, de un trayecto personal por realizar, si hay escucha al otro lado que espera más palabras aún, que no se detiene en lo dicho como puerto definitivo de llegada, y no se apresura tampoco en un afán salvador o pedagógico. Insisto, si alguien muestra interés por dar compañía en el desciframiento de lo vivido.

Y escuchar es eso, es saber crear el silencio de donde nace la palabra, en el que ella se origina, pues acoge su palpitación aún no entregada. Silencio atento, vivo, que compromete y es prueba de compromiso, que es medio y fluir para la comunicación, y no vacío.

Hay veces que escuchando las palabras técnicas que se ponen en juego a la hora de abordar la problemática de los malos tratos una se pregunta dónde están las mujeres que los padecen, donde están sus textos, vivencias e historia, qué lugar se les da en el trabajo, y qué posición de partida se las atribuye a ellas. Recordemos: rehabilitar, reinsertar, nivelar los estados de ansiedad, apoyar en crisis, aportar habilidades sociales, potenciar la autoestima y la inserción sociolaboral, etc. Todo ello es muy valioso en sus contenidos y útil como código entre los/as profesionales, sin duda, si no pierde de vista que el objeto de trabajo, en nuestro caso, es un sujeto. Un sujeto quizá abatido y reducido, incluso a golpes, al sometimiento, en una posición de dependencia feroz, pero sujeto. A pesar quizá de que ella aún no lo sepa. Todas esas pala- 
bras técnicas pueden correr el riesgo de olvidar esa cualidad subjetiva de las mujeres sobre las que se interviene (por cierto, ¿no sería mejor decir con las que se interviene?) y dejarlas tan solas, aisladas o abrumadas como lo estaban antes, y sin haber modificado un ápice la estructura de la dependencia que las llevó a soportar la situación de malos tratos, en la mayor parte de las ocasiones durante largos periodos de tiempo.

María Zambrano acude en nuestra ayuda, no será la única vez a lo largo de estas líneas, recordándonos que hay personas que quitan soledad pero no dan compañía mientras que otras acompañan dejando intacto lo que de puro y de fecundo hay en la soledad. No perder de vista que nadie puede hacer una experiencia en el lugar de otra persona, que las marcas de la vida cobran forma de historia, recuerdo y recurso actual y futuro en la alquimia secreta del interior de las personas, prepara para atender y escuchar, desde la profunda convicción de que la verdad, la explicación y el trayecto a seguir están siempre en el discurso de quien habla, por venir o engendrándose. Pero, eso sí, no surgen ni en el monólogo del aislamiento o en el desconsuelo autista, ni en el callado asentimiento a los dictados bienintencionados, sino pudiendo contar con un otro a quien contar, que espera tanto su palabra como lo que de ella provenga.

En esto la presencia del otro es esencial. No cualquier otro, un otro en tanto que tal, en tanto que Otro con mayúsculas, diferente. Un rostro, como dice Levinas, infinitamente lejano. Otro que no entiende desde los parámetros de la semejanza o la empatía, ni siquiera desde los recursos teórico conceptuales, un otro que sólo atestigua de su interés, de su deseo de saber acerca de quien habla y de acompañarle. Un otro en quien, en el acto de dirigirle el propio relato, en el esfuerzo por hacerse comprender por él, encontramos el apoyo para ir diciendo mejor, más precisa, más extensa y pormenorizadamente nuestra encrucijada, nuestra historia y el ser que alienta en nosotros/as. Hasta tal punto es imprescindible la presencia de ese otro que sin él la propia 
historia no cobra relevancia ni resulta enigmática, es el deseo de saber que ese otro aporta el que señala nuestras vivencias como interrogantes a desplegar para desvelar. Y sucede que, al ir relatando, lo que aún no tenía forma, la cobra. Y el hallazgo es para ambas partes, la que habla y la que escucha. Un otro junto al cual desnacer.

\section{Desnacer}

Esta es otra palabra debida a María Zambrano quien, en un texto escrito a la luz que estalla bajo el cielo de La Habana, desgranó su nacimiento a la vida a través del acto de desnacer ${ }^{1}$. José Ángel Valente también ilumina el sentido de esto que llamamos desnacer: "hallar para las respuestas dadas, sus más secretas preguntas"² y lo sitúa en el ámbito de la conversación, del diálogo, sea cual sea, la forma que este cobre, incluso escrita.

Quien habla a otro/a dejándose ir en ese hablar, se comporta como el poeta, escribe en el aire y crea según su propio estilo. Valente dice del hecho de escribir que supone "la conversión del lenguaje en un instrumento de invención, es decir, de hallazgo de la realidad"3. Y todavía una cita más, esta vez de F. Pessoa: "Pero así es toda la vida... La civilización consiste en dar a algo un nombre que no le compete, y después soñar sobre el resultado. Y, realmente, el nombre falso y el sueño verdadero crean una nueva realidad. El objeto se vuelve realmente otro"4.

En este desnacer la escucha es imprescindible puesto que desnacer es deshacer lo vivido analizándolo, observándolo a través del cristal de la distancia y la extrañeza interesadas, comprometidas con las entrañas, pues el futuro y la existencia se juegan en esa apuesta. No se trata del trayecto de una pregunta pretendidamente intelectual que cala en el caballete de la nariz los impertinentes y cacarea “iqué interesante!”. Desnacer es resistir a la predeterminación de los significados, es suspender los juicios y prejuicios, el murmu- 
llo acostumbrado de la vida, y mirar y oír el mundo con ojos y oídos nuevos, esto es, aquellos que no llevan sobreimpresa de antemano la forma definitoria - la que aporta re-conocimiento- por encima del estímulo registrado por la percepción. Desnacer es nacer al sonido y a la luz aún no acotados en las jaulas de las representaciones ya listas para su consumo.

Esa experiencia puede producir horror, angustia, desamparo, tiene diversos nombres, y no puede hacerse sin compañía, pero deja su huella en la soledad interior, una huella que es de libertad y asombro. El mundo se amplía, las significaciones establecidas vacilan, nace la polisemia y la elección, esto es, el compromiso con un modo de ver y oír que ahora es propio. Propio al tiempo que provisional, puesto que la experiencia realizada deja una marca temporal que relativiza las afirmaciones, sin restarles el empuje necesario para llevar adelante cualquier acción, pero dejándolas impregnadas de futuro, de transformación y cambio posibles, en función de nuevas revisiones. Desnacer es suponer un sentido no desentrañado a aquello que ni siquiera nos causaba curiosidad, a aquello que nos hacía sentir el peso de la evidencia, peso que ahora desde el desnacer sabemos mortífero, mortaja que nos envolvía. Es alentar las intuiciones latentes que aún no han cobrado vuelo, es expresar lo vivido, que de puro vivido no era aún experiencia sino destino.

\section{Desnacer violenta realidades y es violentamente reprimido}

Y hemos entrado de lleno en lo que para mí es la idea central que hoy quería compartir: es precisamente la capacidad para desnacer que las mujeres ejercen desde su posición sexuada y sus efectos respecto del medio que las rodea lo que ha hecho de ellas objeto de persecución y de violencia privilegiado, pues, en términos generales nada se quiere saber de la naturaleza precaria y contingente de las realidades constituidas. Y ellas no han cesado de interrogar esas realidades, con lo cual se han opuesto, subvirtiéndolo, al 
discurso amo imperante, sea éste cual sea, que tiende a su autoconservación.

Las realidades establecidas tienden a persistir mostrándose como evidentes porque nada se quiere saber de que no expresan en sí una verdad última y adecuada del modo de ser y de funcionar del mundo, las personas, los géneros y las relaciones. Nada se quiere saber de que el saber absoluto que anunciara Hegel no existe. Se tolera pensar que aún estamos lejos de él, las propias nociones de perfeccionamiento, desarrollo y progreso se basan en esta idea, pero el saber total como aspiración no puede desaparecer del horizonte ni, digámoslo todo, de la retaguardia. Lo que no resulta tolerable es el contraste con la finitud a que nos enfrenta el hecho de aceptar lo recortado y temporal de aquello que damos en llamar la realidad. Gran parte de las versiones de la historia tienden a hacer de la sucesión de acontecimientos una serie en progreso permanente que culmina a su mayor altura en el presente (dátese este presente en la fecha que se quiera) sin reconocer en esa enumeración de los sucesos los saltos, no de grado sino subversivos, cualitativos, que han dado lugar al cambio de las concepciones y de las realidades. Ya sea encarnado en la idea de la divinidad, ya sea bajo la forma laica de la ciencia, el saber como concepto preserva para la especie humana la ilusión de una adecuación y comunión perfectas y posibles con el entorno.

Bastaría dirigir la mirada a la diversidad cultural, sin la prepotencia etnocentrista del sujeto racional de la Ilustración del que somos producto, para darse cuenta de que el propio concepto de cultura acuna en sus entrañas la muestra de nuestra finitud, la finitud de nuestras concepciones, ésas que creíamos centrales e inamovibles.

Saludar lo finito, alegrarse porque aquello que termina anuncia un nuevo nacimiento, no es sin embargo tarea fácil, el precio a pagar es estar dispuesto a dejar en suspenso todos aquellos signos en los que nos apoyamos como en un bastón para afirmar nuestra existencia, singular y social, para proclamar lo que somos. Y el ser nos es muy preciado. Hurtárnoslo es hacernos 
sentir el abismo bajo nuestros pies, experimentar el desamparo y la vulnerabilidad, registrar en nuestro cuerpo el impacto de la incertidumbre.

Esta tensión no deja de escucharse en las manifestaciones de los saltos generacionales, pero sin duda está presente también en las diferentes concepciones marcadas por el género. La posición femenina, soslayada del poder central, $y$, por tanto, sin la necesidad de autoconfirmación que éste requiere, ha encontrado siempre los huecos, las fisuras en el cuadro de la realidad, sus vacilaciones, por donde asoma la materialidad de lo que aún no tiene nombre y que cuestiona toda la representación del lienzo, o mejor dicho, que tal representación sea toda, y más aún, que sea posible una representación toda y definitiva. No se trata de la muerte del ser en este desnacer, se trata de su reducción a un devenir, se trata de su relativización, si hay algo que muere es lo que corresponde al orden de las esencias últimas.

Esto ha hecho que las manifestaciones de las mujeres hayan sido acalladas, desestimadas o invisibilizadas (o todo lo más, aclamadas como manifestaciones extraordinarias para su sexo) en nombre de los más variopintos argumentos, desde su escasa inteligencia evidenciada por la diferencia en gramos de su masa cerebral, o apelando a la naturaleza femenina más proclive al sentimiento que al entendimiento, hasta su constitucional idoneidad para regir lo cotidiano familiar y su también constitucional incapacidad para los asuntos públicos. Incluso, una vez reconocidas ya como ciudadanas, hecho que se produjo entre otras cosas por la necesidad de no contradicción en los principios fundamentales del sistema y por el empuje de algunas mujeres, sus manifestaciones han sido invisibilizadas en su diversidad y en su capacidad para señalar los restos no atrapados en las conceptualizaciones hechas, a través de diluirlas en el magma de la homogeneidad o reducirlas al campo de la opinión, o incluyéndolas en las líneas generales del sistema, desembarazadas, eso sí, de su carga real de subversión, como ha ocurrido con otras manifestaciones (no olvidemos que la revolución hippie terminó en postales 
y en objetos de consumo en los supermercados). Quizá recordar esto hoy nos resulte anacrónico y suscite sonrisas o rubores, como quien mira atrás en su historia y recuerda las certezas de su edad de la inocencia, quizá sin embargo no sea tan innecesario, si pensamos que cuando se produjeron aquellos argumentos tuvieron el respaldo de la convicción y la lógica al uso, e incluso de la ciencia. Recordarlo nos señala el camino para buscar en nuestro presente las evidencias aceptadas e interrogar la lógica a que responden.

Vayamos por pasos: ese trayecto hacia los orígenes, ese desnacer, que analiza y disuelve a su paso las representaciones y significaciones establecidas que demarcaron nuestros movimientos en la vida tratando de restarles los signos de interrogación en aras de la seguridad y la homogeneidad, sólo puede hacerse porque bien cierto es que habíamos nacido.

Los seres humanos nacemos como sujetos —esto es, como seres que se saben o creen saberse ser, que siempre giran entorno al ser, aun por el hecho de detectar con dolor o angustia que el ser les falta - de la relación con otros seres humanos. El fluido vital que anima nuestra existencia está hecho de relaciones. El ser reconocido por otros nos da un ser, una existencia, y por ello, el otro siempre está en nuestro horizonte, hasta el punto en que la falta de su reconocimiento puede acarrear la pérdida de sentido de nuestra vida. No significar nada para otro puede ser motivo suficiente para renunciar a la existencia. No nos cobija el manto protector de los instintos, hemos permutado su seguridad de bien hacer, su saber adecuado al medio, la supervivencia y la continuación de la especie, por un instrumento, el lenguaje, y éste nos ha herido, nos ha atravesado transformando nuestro núcleo. Nuestro ser, desde esa separación de lo justo, de lo apropiado, de lo que es y debe ser, nuestro ser es siempre proyecto de ser, recuerdo de ser, o como diría María Zambrano, "conato de ser". Nos satisfacemos y nos desgarramos con las palabras que desgranan en nuestros oídos, con el sentido que le damos a los acontecimientos, con la lógica que extraemos de una mirada. Proyecto, recuerdo, huella, 
conato, en definitiva, falta en ser.

En esta falta en ser, carencia original de los seres que hablamos, está, por otra parte, la raíz que nutre la curiosidad, el deseo, la creación, la investigación y transformaciones a que nuestra condición nos impulsa.

El ser nos falta. El Ser, el último, el definitivo, nos falta. Esa falta en ser actúa como motor generatriz del proceso que nos hace buscar el ser. Y este proceso se plasma en una operación precisa, la operación de identificación, en la que encontramos el origen de la causalidad psíquica: el ser nos viene de otro. La posibilidad de llegar a ser o de dejar de ser proviene de alcanzar esa verdad.

La primera identificación lo es al propio lenguaje. Identificarse a ese modo de acceder al mundo que es el modo de lo simbólico es la entraña del primer acto propiamente humano. Mucho antes de que llegue a hablar, el niño responde a la lógica del sentido que establece relaciones entre representaciones y objetos o acontecimientos. Un ruido extraño, no identificado, causará temor, extrañeza o malestar en él y se dirigirá al adulto buscando en éste, no la respuesta, sino el signo de que esa respuesta existe. Si desde el adulto llegan palabras tranquilizadoras o de explicación, aunque aún no las comprenda, bastarán para sedarle. Lo escuchado tiene un sentido y el otro, aquél de quien depende, conoce cuál es. Si, siendo un bebé, nos preocupa que se introduzca en la boca objetos por el riesgo que esto entraña, bastará que saquemos de su campo visual y de acceso motor el objeto en cuestión para que deje de buscarlo y dirija su atención hacia otra cosa: pero al muy poco tiempo sin haber perdido aún su condición de bebé, su entrada en el campo del sentido se hace patente pues ya no es necesaria la presencia del objeto para que éste siga teniendo existencia psíquica. Así, si le retiramos dicho objeto llorará o lo buscará. 
Hegel decía que el concepto es el tiempo de la cosa, parafraseándole diríamos que la palabra, que introduce el sentido en todos los hechos humanos, es el tiempo del objeto. El objeto entra en la historia y su presencia y su existencia no dependen ya del acceso perceptivo inmediato, su recuerdo ligado al lenguaje, su definición, su impronta simbólica en la psique, le hacen existir más allá de lo sensible. Esto se complejiza cada vez más y lleva por ejemplo a la posibilidad de definir y tramitar elementos no perceptibles por los sentidos de cuya existencia hoy nadie dudaría, y podemos poner ejemplos tanto del campo de la ciencia como de la vivencia, desde las partículas subatómicas hasta eso que llamamos serenidad, etc.

Desde la perspectiva psicoanalítica esta identificación primordial se denomina "identificación al significante". El significante es ese elemento de la estructura del lenguaje que produce, conjugado con otros significantes, un significado, la construcción de una significación. Significante es todo signo lingüístico, pero también el vuelo de una falda al pasar, unas gafas que descienden y descubren una mirada, una puerta entreabierta, etc., todo aquello que nos llama y extraña, ese algo a lo que en sí mismo no podemos dar un contenido representativo claro pero que, ligado a otras improntas en una conexión discursiva, puede crearlo. Podríamos decir que los significantes son como las pinceladas de una pintura, tomadas una por una no dicen nada, es su articulación la que da lugar a una representación. Así, definimos el significante como aquello que no significa nada pero que tiende a la significación. En esta primera identificación se asienta eso a lo que antes me he referido, que todo movimiento, interno o externo, es para el ser humano significativo, aun cuando desconozca o no haya creado la significación correspondiente, no duda que tiene un sentido.

Este nacer al medio simbólico, medio humano por excelencia, es igual para hombres y mujeres. Todos aprendemos a tomar las cosas por los símbolos que las representan, todos nacemos al sentido. Si hubiera que hablar de 
alguna violencia original, primordial, tendríamos que situarla en este punto. Es la violencia del lenguaje la que extrae al género humano del mundo de la adecuación natural, de los instintos, y lo lanza al mundo de los conatos de ser, del sentido, de la curiosidad, en el que siempre algo falta para cuadrar las cuentas y cerrar.

El ser que el lenguaje nos ha arrebatado es ese ser silente que no se sabe ser, que simplemente existe. Desde el momento en que el ser se nombra desaparece la posibilidad de su completud autosuficiente puesto que el nombre que señala en dirección a lo nombrado, marca a su vez la distancia que con ello mantiene. Nombre y ser jamás son una sola y misma cosa, por ello, en el campo del ser siempre habrá una falta en ser. Y es en esta falta donde encontramos tanto el motor de una búsqueda como el origen de la acomodación a lo ya representado.

Ingresados ya en el campo del sentido, gracias a que nos fue dado un ser y porque ya sabemos que el ser se da, estaremos en condiciones de dárnoslo. No requeriremos de las respuestas de ningún otro encarnado, el otro estará en nuestro interior, y estará como extraño, como ajeno a nosotros mismos, como potencia, como significante que exige entrar en relación con otros para dar lugar a un sentido. En el punto en que nos damos cuenta de la historia que nos ha sido hecha podemos comenzar a interpretarla, a construirla nosotros, a desnacer. Comienza la relación con nuestra propia subjetividad, con el íntimo extranjero que nos habita y nos invita a ir más allá. Si bien es cierto que ese otro requiere de un asentamiento encarnado en cada crisis, en cada momento vital de pasaje de un estado a otro, de una posición a otra, de ahí la importancia de la escucha a la que nos hemos referido antes: quien escucha, como el lienzo en blanco, recibe las improntas de nuestra extranjeridad interior y nos permite jugar con la distancia que crea perspectiva. 
En ese punto, el ser afincado molesta. Pedro Salinas decía en uno de sus versos: "lo que eres me distrae de lo que dices". El ser nos pesa como encierro y nos oculta de nosotros mismos y así abrimos la puerta a otra cosa, a lo que destituyéndole nos promete sin embargo un porvenir, otros seres.

De la experiencia de la vida, esa memoria de lo que hemos sido que persiste como sedimento en nuestra realidad de hoy, dice Ortega y Gasset: "haber sido algo es la fuerza que más automáticamente impide serlo... De donde resulta que el ser del hombre es irreversible, está ontológicamente forzado a avanzar siempre sobre sí mismo, no porque tal instante del tiempo no puede volver, sino al revés: el tiempo no vuelve porque el hombre no puede volver a ser lo que ha sido". Fijémonos bien que no dice qué es lo que impide ser otra cosa sino lo que impide, precisamente, ser lo que ya se ha sido.

Lo que denominamos experiencia de la vida es en parte lastre que se arrastra y cierra la perspectiva de nuestra mirada y de nuestros actos, $y$, en parte, equipaje, material, memoria, que empuja y se abre a la creación y el futuro cuando se toma como punto de partida para desnacer, como materia, arcilla para modelar, pasta que puede ser reamasada para servir de sustrato a una nueva figuración.

Todo el entramado sociocultural y de poder, y cada ser humano en el abismo del miedo y el recelo interiores a no ser o a dejar de ser, nada quiere saber precisamente de esa irreversibilidad que implica necesariamente en sí misma una precariedad y también una imposibilidad, o por lo menos una dificultad importante, para establecer predicciones. Cuando el peso de lo sido y establecido, de lo ya conocido, se densifica, denuncia el miedo a lo extraño interponiendo un obstáculo a lo nuevo.

Esto es lo que he denominado en otro espacio ${ }^{6}$ violencia represora o conservadora pues tiende a perpetuar un ser, un modo de ser ya establecido. La raíz de esta violencia se afinca en otra identificación, la identificación a las 
imágenes y significaciones ya construidas y compartidas, que pueden ser objeto de intercambio entre semejantes. Violencia imaginaria, por tanto, y narcisista en su núcleo. Violencia de lo compartido, de lo gregario, de lo semejante, de lo común. Ámbito en el que las diferencias sólo son incorporadas en una dimensión de medida: tener más o menos, ser más o menos esto o lo otro, donde la diferencia como otredad radical no tiene cabida. Violencia que todo modo instituido de relación, que todo paradigma cultural, ejerce sobre los sujetos que se recogen en su ámbito. Violencia también que cada ser humano ejerce sobre sí mismo en los puntos en que sus propias manifestaciones o las de lo que le rodea le hacen desconocerse, extrañarse de sí mismo (la violencia, por ejemplo, que en ocasiones nos hace terminar por decir "iqué tontería he dicho!" cuando algo inesperado ha surgido de nuestros labios, sin nuestro consentimiento ni voluntad). Violencia, asimismo, que cada ser humano está dispuesto a ejercer sobre otro cuando define en él el punto de origen de aquello que desestabilizó su autoconocimiento y su saber sobre el medio, a veces por el simple hecho de abrirlo a otras posibilidades o interrogarlo.

Ésta es la violencia que sufren las mujeres por parte de sus compañeros (no hablo ya de la violencia originada en una patología psíquica, aunque cabría decir que en sus líneas estructurales es homóloga a la aquí descrita, salvo que su puesta en ejercicio salta las barreras de la comprensión común) y también la que, en ocasiones, ejercen sobre ellos cuando, identificadas a sus roles de género y a los patrones imperantes como punto de anclaje vital para su existencia, les exigen un cumplimiento exacerbado de los contenidos de aquellos otros roles en lo cuales ellos también están presos.

Lo que busca reprimir esta violencia son las incógnitas que las respuestas ocultan, la pluralidad de perspectivas y verdades, lo singular, lo no contemplado y el cambio. No le interesa la creación ni siquiera la producción, apunta tan sólo a la reproducción y perfeccionamiento de lo sabido, de la realidad que ya está materializada en pautas y modos de hacer y de ser. La 
incógnita únicamente se tolera situada dentro del los parámetros del saber asentado y en cuanto afín a la tendencia de su progreso.

Esta violencia se dirige al control y, si lo considera necesario, a la exterminación de todo aquello que atenta contra la estabilidad del ser. Así, el agresor siempre se justificará alegando haber sido agredido en primer instancia, y en cierto modo así ha sido, lo que ocurre es que nada tiene que ver esa otra violencia, creadora, simbólica, que a lo que apunta es a la libertad y la ruptura de cadenas, con la que se empeña por reforzar las soldaduras de los eslabones. La violencia creadora señala en la dirección de la libertad propia y del otro, la conservadora, creyendo defender el orden que fundamenta la existencia, asfixia a los sujetos en el corsé de las imágenes y tan sólo se defiende de la presencia de lo otro, lo diferente, lo no esperado, lo nuevo.

Por el contrario, usar de la memoria para desnacer, partiendo hacia ella con el asombro como compañero, es crear un vacío de significados 1leno de sentidos potenciales. Es un acto de subversión de lo instituido, instituyente en sí de una nada desde la que observar. Esta nadificación de lo dado, este no tomarse demasiado solemnemente - pero sí muy en serio, muy vitalmenteni la realidad que nos ha tocado vivir ni nuestra realidad interior, este contar con que ambas son el vehículo de que nos hemos dotado para deambular por la vida y encontrarle un sentido y que, por tanto, son sustituibles, es lo que denomino violencia creadora o violencia simbólica.

También esta violencia es fruto de una operación de identificación, pero en este caso, en lugar de una identificación a las significaciones establecidas, lo que se produce es una identificación al silencio entrañado en toda significación, esto es, a lo que ella no termina de decir, a lo que falta por representar en la imagen que ella constituye, a la promesa de otra cosa aún. 


\section{Identificación al silencio y creación}

El hecho de desnacer, de ir desnaciendo al hacer memoria, mirada y oído, desnuda y revela que los conceptos universalistas ocultan actos de dominación. Se violenta así el dominio del amo. Esta violencia creadora es la de la identificación a un silencio, el silencio que cada significado acalla pero no totalmente, el silencio que está entrañado en todas y cada una de las significaciones que tejen la trama del aire que respira nuestro ser. Ese silencio nos habla, nos dice que no está todo dicho y sobre todo, que no es posible decirlo todo, libera así la palabra de su anclaje y conexiones dados y la vuelve instrumento de creación y juego. Ese silencio nos habla desde la sorpresa de lo que no encaja con lo esperado, desde la relación que se resiste a desvelar un secreto cuando ya creíamos dominarla, desde los misterios que surgen en el cotidiano, en sus repeticiones siempre diferentes.

La identificación al silencio encerrado en las significaciones desvela que las respuestas no son otra cosa que interpretaciones y que, por tanto, están abiertas a otras nuevas; denuncia que "la realidad del mundo no es, sino que se construye a través de las interpretaciones"

Esta identificación al silencio en las significaciones es el soporte esencial de todo proceso de escucha, no es sino desde ella que alguien puede llegar a escuchar verdaderamente a otra persona: el respeto por las significaciones que se entrelazan en el discurso de quien habla permite que ellas se desplieguen en toda su dimensión y que gracias a ello al hacerlo denoten también los puntos de silencio. Esos puntos serán el regalo que quien escucha ofrece al que habla, para que siga hablando y, al hacerlo, investigue y cree.

Volviendo a María Zambrano: "El poder condensa el silencio y lo rompe, violentándolo con palabras que van cargadas con la pretensión de ser una, una sola palabra que acabe con todas las demás, y aún con el silencio mismo, ocupándolo de una vez para siempre. Es él, el solo poder, quien puede 
reproducir la pura totalidad con la pretensión de absoluto en espacio, tiempo y ser... pero su imposibilidad desata la violencia, la reiterada violencia del poder que reitera en el tiempo, instante a instante, lo que no puede lograr en un sólo instante absolutamente"s.

Lo que el poder no puede lograr nunca completamente es hacer cesar el silencio que estalla en lo dicho o representado y que, si es escuchado, puede hacer quebrar ese dicho o esa representación y dar a luz otros. Algo siempre queda por decir. La violencia creadora, violencia simbólica, devuelve el silencio a su lugar, lugar de útero, de creación. J. Ángel Valente dice: “Crear es generar un estado de disponibilidad, en el que la primer cosa creada es el vacío. Pues lo único que el artista acaso crea es el espacio de la creación”9.

Todos los productos que surgen de poner a trabajar el instrumento de lo simbólico, cada una de las representaciones logradas, llevan la marca del silencio, puesto que el medio de lo simbólico se define precisamente por representar aquello que escapa de su registro, esa materia, tangible o no, pero existente que son los objetos los sujetos, los vínculos. Todo acto simbólico consiste en poner en contacto dos materialidades diferentes, la materialidad del significante y la materialidad de los objetos, pero, evidentemente, poner en conexión no significa subsumir o absorber. El objeto representado no entrega jamás su último secreto, escapa siempre una parte de su misterio, y esa parte que no se alcanza a representar emerge en lo simbólico como silencio, esto es, como llamada a un nuevo decir. Es cierto que este nuevo decir, esta nueva construcción cuando llega, tiende a creer que ha llenado la laguna de silencio, esto es, que ha alcanzado la adecuación. Sin embargo, haber atravesado por el derrocamiento de la realidad anterior deja una huella importante: el horror a la pérdida de los apoyos, de lo familiar y conocido, a la pérdida del ser, ya no es tan vigoroso y la esperanza de construir nuevas realidades permite enfrentarlo. 
Los discursos feministas sobre el género al abordar cómo se producen, reproducen y mantienen los sistemas de género, cómo y por qué se hacen dominantes, suponen ya un cuestionamiento de las evidencias instaladas, de los modos de relación que se habían naturalizado hasta el punto de confundirse con esencias. La crítica feminista ha partido así en sus producciones de una identificación al silencio que yace en las significaciones. Jane Flax ${ }^{10}$ nos plantea que el primer paso a la hora de abordar el estudio e investigación del género es confrontarse con las resistencias internas, incorporadas subjetivamente, y que, paradójicamente, adoptan la forma de facilitaciones.

Todo aquello cuyo acceso nos resulta facilitado supone un obstáculo a la investigación. Ser mujeres para nada nos pone en mejores condiciones objetivas para abordar las cuestiones de género. Ser mujeres, de acuerdo a los patrones de género en que este ser se ha constituido, no es otra cosa que solidarizarse con el poder que ha acallado los silencios, los misterios de las diferencias. El riesgo que corren las teorías feministas a medida que se consolidan, como lo corre todo pensamiento que se expresa y perfecciona, es el de venir a sustituir una ilusión de totalidad por otra, una ilusión de explicación definitiva por otra.

La violencia de la identificación al silencio es la violencia que ejercen preferentemente las mujeres pero también aquellos otros que, como ellas, han quedado de una u otra forma excluidos, o no claramente identificados en las relaciones privilegiadas del poder, que requieren de dos polaridades, el amo y el esclavo. Uno y otro contribuyen a preservar las condiciones de reproducción de la estructura. El amo extrae su saber del esclavo y le sostiene en posición de dependencia, nutriéndole; le defiende de otros amos, como uno más de sus dominios, y en ello estriba su pago por conservar su situación de privilegio, pues arriesga su prestigio y, llegado el caso, la vida (he dicho la vida, no la existencia, porque es precisamente la vida lo que está dispuesto a arriesgar para que la existencia de su ser y sus cualidades no corran peligro). 
Pero el esclavo juega también su papel, cumple con las encomiendas del amo, ofreciéndole bienes y, mientras, espera secretamente su muerte, o acaricia la idea de sublevación, que le conducirían a ocupar su lugar. Hay un refrán que reza: "los mismos perros con diferentes collares". La alternancia es cuestión de semejantes u opuestos en un par indisoluble y el poder que disputan no se altera en sus características fundamentales, sino tan sólo en su apariencia. Todo dualismo constituye un callejón sin salida.

No, no es en la dialéctica del amo y del esclavo en la que se genera la posibilidad de creación que, en principio y necesariamente, es creación de una nada, de un vacío de sentido, que estableciéndose hace cesar el poder (tanto del amo como del esclavo, el poder por tanto de un discurso que los requiere a ambos) y alumbra la potencia.

Son quienes han quedado enredados al discurso dominante, (como dice J. Lacan, "Discurso Amo", de cuyas encarnaciones hay multitud a lo largo de los siglos y a lo ancho de las organizaciones sociales, tantos como tantas diferentes podamos enumerar) pero no anudados claramente en él, por sus condiciones históricas, sociales o personales, quienes ocupaban una posición marginal en ese discurso, los que están en mejores condiciones para hacer cesar su poder poniéndolo en tela de juicio, dejándolo en suspenso, esto es, para desnacer y crear. No es posible hoy hacer un recorrido histórico de los lugares y funciones atribuidos al colectivo femenino a lo largo de los siglos y según las diferentes organizaciones sociales. Sin embargo, sí cabe apuntar que el lugar socialmente subordinado atribuido a la mujer en la sociedad de parámetros patriarcales ha hecho de ella una extranjera ubicada en su núcleo más íntimo. Lo cual también la ha promovido a la posición de blanco preferente de las defensas armadas del sistema, a través de la violencia conservadora que éste ejerce y deja ejercer. De ahí podríamos extraer, entre otras, la connivencia, benevolencia, e incluso solidarización, que en muchos sistemas de justicia se aprecia respecto de la violencia ejercida sobre las mujeres, en el hecho de velar los malos tratos tras el parapeto de lo privado ${ }^{11}$. 


\section{Cada mujer es otra}

Las mujeres con su presencia ejercen la violencia de lo no común y pueden ejercerla desde una privilegiada posición, la de aquéllas que han experimentado en su propio cuerpo e identidad el embarazo de lo incierto, de lo extraño, de lo que escapa a lo definido por cualquier pauta social, cultural, familiar o personal.

Cada mujer es otra para sí misma, aunque muchas de nosotras hagamos lo imposible por olvidarlo. Es otra para sí, diferente de aquella que tan bien conoce, porque lo que la define socialmente la vincula necesariamente a la maternidad, y en la experiencia de esa maternidad cada mujer reconoce que su ser mujer queda constreñido: donde impera la madre, la mujer se desvanece. No es que la maternidad no sea una experiencia única y propia de las mujeres, se trata de que se ha querido agotar en ella la especificidad de lo femenino y precisamente en ese punto la parte mujer escapa de la definición.

La mujer-madre es la pareja esclavo del hombre-amo. Se la ha dibujado cercana a la naturaleza, como misterioso reloj que pone en hora la voluntad de vivir y su imagen se ha cargado de instintos maternales, base que se ha considerado sólida para afirmar su "otra sensibilidad afectiva", y, por otra parte, este asimilarla a la naturaleza y a los instintos ciegos de esa voluntad inconsciente ha hecho que se confundan las cosas de mujeres con cosas de hembras y que, por ello, las mujeres hayan sido vistas como peligrosas para el orden social establecido y requiriendo la guía de la razón masculina.

Este acercamiento social de la mujer a la naturaleza a través de la maternidad ha hecho también que en muchas organizaciones sociales a ella le hayan sido destinados los quehaceres relativos a esos hitos, naturales al tiempo que misteriosos, que se suceden una y otra vez en el despliegue de las vidas humanas: el nacimiento, la sexualidad y la muerte. El cuidado y arreglo del niño y del cadáver ha sido cosa de mujeres, así como los ciclos de lo prohi- 
bido y lo permitido del encuentro sexual han sido marcados por las manifestaciones de su cuerpo. Por otra parte, estos tratos íntimos con la materialidad de los misterios del cuerpo han hecho también de las mujeres entes peligrosos por estar conectados con las fuerzas del más allá de la razón: diosas y brujas, heces de satán o santas ideales, todas ellas poderosas y por ello merecedoras de aislamiento. Ya sea la reja de la adoración o la barrera de fuego que devora su carne lo que las haya circundado, las ha mantenido al margen.

Cierto que la maternidad proporciona una experiencia, mujer a mujer, absolutamente única. Albergar y producir en su seno el enigma de la creación - por muy explicado científicamente que esté hoy día-, asistir en su tránsito a la emergencia de un cuerpo diferente aún siendo el propio, cobijar en las entrañas a lo más suyo, tanto que su torrente sanguíneo es el de ella, y, al tiempo, hacer la experiencia de estar habitada por un desconocido, todo ello son vivencias que acercan a cada mujer al silencio de las significaciones, que exigen de ella dar una versión y una historia propias. No gesta tan sólo una criatura, gesta toda una historia. Pero, precisamente todo eso, la aleja de la posibilidad de instalarse confortablemente en el estereotipo, cuando lo hace es huyendo de la angustia. En todo caso, de lo que no hay duda es de que la maternidad no alcanza para definir lo que una mujer sea.

La otra experiencia que también anida en el cuerpo, no cuerpo biológico sino cuerpo simbólico, cuerpo de relación, es la que hace referencia a que en la imagen de la mujer comparada con la del cuerpo del hombre en ese punto del desarrollo en que todavía no hay otra diferencia, la mirada nos dice que algo falta, cuando en realidad no es así. La perspectiva engaña, las apariencias de la imagen, de lo inmediato y evidente son respuestas a atravesar. También aquí cada mujer es otra para sí misma que aquella que dicen que es: le muestran su carencia, exhiben del otro lado lo que supuestamente a ella le falta, y ella, en lugar de carencia sabe que lo que existe es diferencia. Aunque de este saber no haya podido apropiarse, ni se le haya facilitado el hacerlo, 
sino tras ardua lucha entre sus vivencias y las significaciones sociales en que quedaban enterradas. De esa falta aparente han nacido para el discurso social la estipulada debilidad de las mujeres, su necesidad de compañero y/o hijo que le ofrezca protección y compense aquello de lo que carece, el corto alcance de sus propósitos, etc. En su intimidad, el peso de sobrellevar esa falaz falta que no lo es le abre el camino tanto a descubrir el mecanismo del acallamiento - que a través de imponer silencio busca negar existencia a lo que perturbaría el orden establecido-, como a abrir su espíritu a la identificación al silencio entrañado en toda significación, ese otro silencio que es promesa de otras cosas, de otras significaciones posibles, pues es un silencio sonoro que denuncia la fragilidad y precariedad de las evidencias, de las imágenes que parecen o pretenden decirlo todo.

Así, resulta que esos dos anclajes en el cuerpo de los que el cuerpo social (marcado sexualmente como masculino) ha hecho uso para definir las líneas de los patrones de género femeninos se muestran extraños para la intimidad de cada mujer, aunque se haya visto determinada a identificarse con ellos o aunque haya tratado de hacerlo de buen grado. Algo siempre escapa, no se ve circunscrita en ellos. El mundo de las imágenes y las apariencias, de lo inmediato, conforma un marco muy pobre respecto de la riqueza de vivencias que trata de contener. Es más, gracias a lo inagotable de esas dos encrucijadas corporales, con las que no puede no toparse, se asoma al núcleo del silencio, a lo no explicitado sino acallado, a lo que se resiste a ser atrapado en la trampa de lo definido y, desde ahí, cuestiona y crea.

Lo mismo podríamos decir quizá de los símbolos fálicos que tratan de ceñir la masculinidad y dejar cerrado al varón cualquier otro camino distinto del de testimoniar de su virilidad. Lo que ocurre a este respecto, sin embargo, es que la definición general de lo humano y la particular del género masculino han compartido - pues nacieron para cumplir esa función - las características esenciales y, por tanto, el hecho de ser varón ha participado de los valo- 
res más apreciados, lo que conlleva posiciones de privilegio con relación al poder. La diferencia quizá estribe tan sólo, o ni más ni menos, en el hecho de que los corsés han sido cortados y cosidos para dar satisfacción a uno de los géneros, sin saber que en esa satisfacción se encierra también una renuncia.

La violencia de lo no común, de la identificación al silencio, causa horror cuando se está dispuesto a toda renuncia y, en primer término, a la de la propia libertad en aras de la seguridad. En ese momento el aparato de destrucción, la violencia represora, se pone en marcha y la mujeres hemos sido uno de sus objetivos favoritos.

Proponer desde un modelo de intervención con mujeres que han sufrido esta clase de violencia el instrumento de la escucha es apuntar a generar condiciones para desnacer, para ejercer esa otra violencia que es creadora de nuevas realidades. Cuando desde el ámbito del trabajo social hablamos de la necesidad del concurso activo del usuario/a en la resolución de su problemática, lo hacemos porque es sabido que la aplicación de programas y el acercamiento de recursos comunitarios para la resolución de una problemática son esenciales, pero también que si los recursos acercados no están en consonancia con un trayecto personal de elaboración, asunción y deseo de resolver la dicha problemática el efecto de todo el proceso de intervención o bien será ineficaz en sus resultados respecto de los objetivos propuestos (por el equipo o el profesional) o, tras una aparente resolución de la problemática, esta insistiría en la misma dimensión o en otra terminando por dar lugar a esa dependencia de las instancias de bienestar social que tan bien conocemos. Se cronifica pues la situación de dependencia. No se trata sólo de acercar recursos, sino de generar además las condiciones internas en los sujetos que les permitan hacerse cargo de esos recursos como propios. 


\section{NOTAS}

1. María Zambrano, Delirio y destino. Madrid: Ed. Mondadori

2. José Ángel Valente, "Carta abierta a José Lezama Lima” en La piedra y el centro.

Madrid: Ed. Taurus.

3. José Ángel Valente, Las palabras de la tribu. Madrid: Ed. Tusquets.

4. Fernando Pessoa, Libro del desasosiego. Barcelona: Ed. Seix Barral.

5. Ortega y Gasset, La historia como sistema. Ed. Sarpe.

6. Lydia Gómez Valverde, "Violencia y mujer: ¿por qué son términos asociados?” en I Jornadas sobre la violencia de género en la sociedad actual. Valencia: Ed. Generalitat Valenciana, Consellería de Bienestar Social, Dirección General de la Mujer.

7. Gianni Vattimo, "Entrevista con Gianni Vattimo", en Revista de la Asociación española de Neuropsiquiatría, $\mathrm{n}^{\circ}$ 54, julio/septiembre, 1995.

8. María Zambrano, "La palabra y el silencio" en Revista Asomante. S. Juan de Puerto Rico, octubre/diciembre, 1967.

9. José Ángel Valente, Material Memoria. Madrid: Ed. La gaya ciencia.

10. Jane Flax, Psicoanálisis y feminismo: pensamientos fragmentarios. Madrid: Ed.

Cátedra.

11. Soledad Murillo, El mito de la vida privada. Madrid: Ed. siglo XXI.

\section{BIBLIOGRAFÍA}

Benhabib, S. y Cornell, D. (1990). Teoría feminista y teoría crítica. Valencia: Eds. Alfons el Magnànim.

Butler, J. (1990). Gender trouble. Feminism and the subversion of identity. New York: Routledge.

Chodorow. (1989). Feminism and Psychoanalytic Theory. Yale: Yale University Press.

Ferreira, G. B. (1992). Hombres violentos, mujeres maltratadas. Buenos Aires: Ed. Sudamericana.

Fisas, V. (comp.) (1998). El sexo de la violencia. Barcelona: Icaria.

Flax, J. (1995). Psicoanálisis y Feminismo. Pensamientos fragmentarios. Madrid: Ediciones Cátedra.

Freud, S. (1986) El malestar en la cultura, en Obras Completas, volumen 
XXI. Buenos Aires: Amorrortu.

- (1986 b), "La feminidad". En Nuevas conferencias de introducción al psicoanálisis, en Obras Completas, volumen XXII. Buenos Aires: Amorrortu.

Gómez Valverde, L. (1996). “La mujer no existe, insiste por existir”. En Asparkía $\mathrm{n}^{\mathrm{o}} 6$ (Revista de investigació feminista). Actes del curs: Dona, dones art i cultura. Castellón de la Plana: Publicacions de la Universitat Jaume I.

- (1997) “Violencia y mujer, ¿por qué son términos asociados?”. En $1^{a}$ Jornadas: Sobre la violencia de género en la sociedad actual. Ponencias. Valencia: Generalitat Valenciana, Consellería de Bienestar Social. Dirección General de la Mujer.

Lacan, J. (1981). El Seminario. Libro 20. Aún. Barcelona: Paidós.

-(1992). El Seminario. Libro 17. El Reverso del Psicoanálisis. Barcelona: Paidós.

Lerner, G. (1990). La creación del patriarcado. Barcelona: Crítica.

Maquieira, V. y Sánchez, C. (comps.) (1990). Violencia y sociedad patriarcal. Madrid: Ed. Pablo Iglesias.

Rivera Garretas, M. M. (1994). Nombrar el mundo en femenino. Barcelona: Icaria.

VV. AA. (1989). Hombres y mujeres en el pensamiento occidental, Vol. II. Madrid: Ed. Universidad Autónoma de Madrid. 